\title{
Shared Mechanisms for Opioid Tolerance and a Transition to Chronic Pain
}

\author{
Elizabeth K. Joseph, David B. Reichling, and Jon D. Levine \\ Departments of Medicine and Oral Surgery, Division of Neuroscience, University of California, San Francisco, San Francisco, California $94143-0440$
}

Clinical pain conditions may remain responsive to opiate analgesics for extended periods, but such persistent acute pain can undergo a transition to an opiate-resistant chronic pain state that becomes a much more serious clinical problem. To test the hypothesis that cellular mechanisms of chronic pain in the primary afferent also contribute to the development of opiate resistance, we used a recently developed model of the transition of from acute to chronic pain, hyperalgesic priming. Repeated intradermal administration of the potent and highly selective $\mu$-opioid agonist, [D-Ala ${ }^{2}, N$-MePhe ${ }^{4}$,gly-ol]-enkephalin (DAMGO), to produce tolerance for its inhibition of prostaglandin $\mathrm{E}_{2}$ hyperalgesia, simultaneously produced hyperalgesic priming. Conversely, injection of an inflammogen, carrageenan, used to produce priming produced DAMGO tolerance. Both effects were prevented by inhibition of protein kinase $\mathrm{C} \varepsilon(\mathrm{PKC} \varepsilon$ ). Carrageenan also induced opioid dependence, manifest as $\mu$-opioid receptor antagonist (D-Phe-Cys-Tyr-D-Trp-Orn-Thr-Pen-Thr- $\mathrm{NH}_{2}$ )-induced hyperalgesia that, like priming, was $\mathrm{PKC} \varepsilon$ and $\mathrm{G}_{\mathrm{i}}$ dependent. These findings suggest that the transition from acute to chronic pain, and development of $\mu$-opioid receptor tolerance and dependence may be linked by common cellular mechanisms in the primary afferent.

\section{Introduction}

A common clinical observation is that a critical transition occurs in patients when opioid-sensitive "persistent acute pain" state transforms into an opioid-resistant "chronic pain" syndrome. Why analgesics are often less effective for the treatment of chronic than acute pain (Kalso et al., 2004; McCleane and Smith, 2007; Rosenblum et al., 2008) remains a critically important question, the answer to which could lead to improvement in the treatment of millions of patients with chronic pain syndromes.

We have developed a model of the transition to chronic pain, known as hyperalgesic priming (Aley et al., 2000), in which there is a long-lasting neuroplastic change in the signaling pathway mediating proinflammatory cytokine-induced nociceptor sensitization and mechanical hyperalgesia, at the site of a previous inflammatory insult (Reichling and Levine, 2009). Induction of hyperalgesic priming in the peripheral terminals of primary afferent nociceptors is mediated by protein kinase $\mathrm{C} \varepsilon(\mathrm{PKC} \varepsilon)$. The development of tolerance and dependence in $\mu$-opioid receptor signaling also involves PKC (Mestek et al., 1995; Kelly et al., 2008) and switching between $\mathrm{G}_{\mathrm{s}}$ - and $\mathrm{G}_{\mathrm{i}}$-mediated signaling pathways (Kalso et al., 2004; Chakrabarti et al., 2005; Wang and Burns, 2006; Rosenblum et al., 2008) that may also occur in sensory neurons (King et al., 1999). Therefore, we hypothesized that the reason chronic pain is associated with resistance to opiate analgesics is that both phenomena arise from closely related changes in intracellular signaling pathways in primary afferent nociceptors.

\footnotetext{
Received Nov. 7, 2009; revised Jan. 2, 2010; accepted March 1, 2010.

This work was supported by a grant from the National Institutes of Health.

Jon Levine is named on a patent for the use of PKC $\varepsilon$ in the treatment of pain.

Correspondence should be addressed to Dr. Jon D. Levine, Department of Medicine, C-522/Box 0440, University

of California, San Francisco, San Francisco, CA 94143-0440. E-mail: levine@itsa.ucsf.edu.

DOI:10.1523/JNEUROSCI.5530-09.2010

Copyright $\odot 2010$ the authors $\quad 0270-6474 / 10 / 304660-07 \$ 15.00 / 0$
}

In the present study we tested this hypothesis by determining whether: 1) induction of opioid tolerance, by repeated administration of a $\mu$-opioid agonist will also induce hyperalgesic priming, 2) induction of hyperalgesic priming by inflammation also induces opioid tolerance and dependence, and 3) interactions between the transition from acute to chronic pain and the development of opioid tolerance and dependence are mediated by PKC $\varepsilon$ and $\mathrm{G}_{\mathrm{s}} / \mathrm{G}_{\mathrm{i}}$ switching in G-protein signaling in primary afferent nociceptors.

\section{Materials and Methods}

Animals. Experiments were performed on adult male Sprague Dawley rats (220-300 g; Charles River). Animals were housed 3 per cage, under a $12 \mathrm{~h}$ light/dark cycle, in a controlled environment at the University of California, San Francisco animal care facility. Food and water were available ad libitum. All testing was done between 10:00 A.M. and 4:00 P.M. Experimental protocols, approved by the University of California, San Francisco Committee on Animal Research, conformed to National Institutes of Health Guidelines for the Care and Use of Laboratory Animals.

Nociceptive testing. The nociceptive flexion reflex was quantified with a Basile Analgesymeter (Stoelting), which applies a linearly increasing mechanical force to the dorsum of a rat's hindpaw. Nociceptive threshold, defined as the force in grams at which the rat withdraws its paw, is the mean of 3 readings taken at $5 \mathrm{~min}$ intervals. For nociceptive testing, rats were placed in cylindrical transparent restrainers designed to provide adequate comfort and ventilation, allow extension of the hind leg from the cylinder, and minimize stress. All rats were acclimatized to the testing procedure. Each paw was treated as an independent measure and each experiment performed on a separate group of rats. The results are expressed as percentage change from baseline mechanical nociceptive threshold determined before administration of test agent.

Drugs and their administration. Drugs used in this study were prostaglandin $\mathrm{E}_{2}\left(\mathrm{PGE}_{2}\right.$; a hyperalgesic agent that directly sensitizes nociceptors), $\gamma$ carrageenan (CARR, inflammogen) and pertussis toxin (PTX, a selective inhibitor of $\mathrm{G}_{\mathrm{i}}$-proteins) from Sigma; $\left[\mathrm{D}-\mathrm{Ala}^{2}, \mathrm{~N}-\mathrm{MePhe}^{4}\right.$,glyol]-enkephalin (DAMGO) (a $\mu$-opioid receptor agonist) from Research 


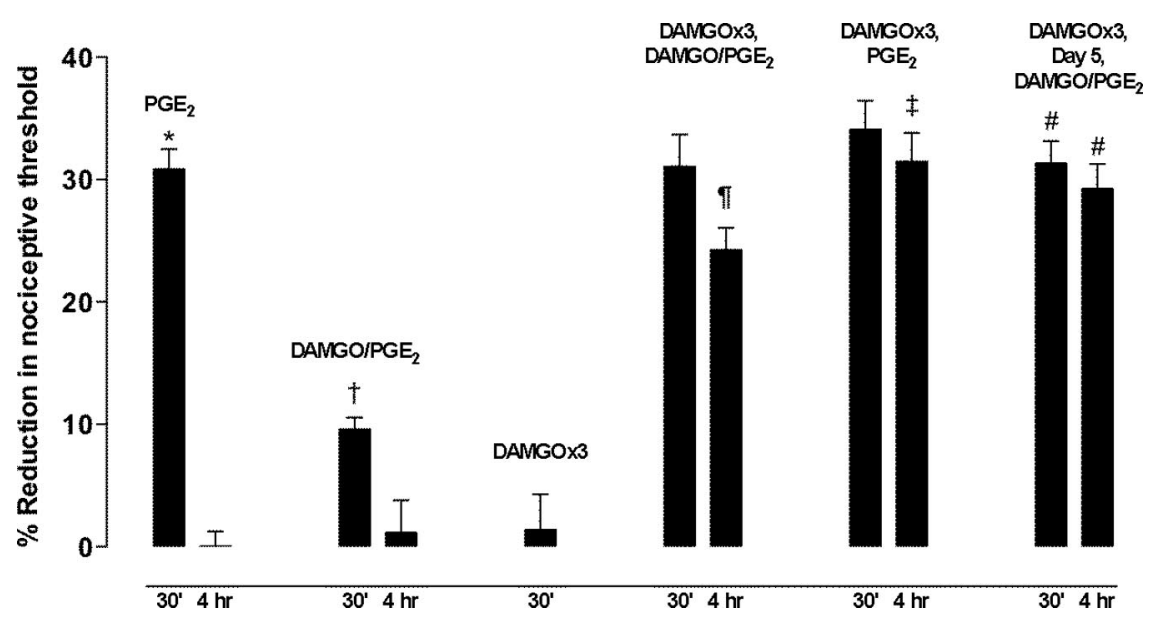

Figure 1. In naive control rats prostaglandin $\mathrm{E}_{2}\left(\mathrm{PGE}_{2}\right) 100 \mathrm{ng}$ induces mechanical hyperalgesia ( ${ }^{*} \mathrm{p}<0.001$ compared with baseline at $30 \mathrm{~min}\left(30^{\prime}, n=12\right)$ that lasts $<4 \mathrm{~h}$. When injected with $\mathrm{PGE}_{2}, \mu$-opioid receptor agonist DAMGO $(1 \mu \mathrm{g})$ significantly inhibited $\mathrm{PGE}_{2}$ hyperalgesia (DAMGO/PGE ${ }_{2}{ }^{\dagger} p<0.001$ compared with $\mathrm{PGE}_{2}$ alone, $n=6$ ). Following DAMG0x3 treatment, at the fourth hour, injected with $\mathrm{PGE}_{2}$, DAMGO no longer inhibited $\mathrm{PGE}_{2}$ hyperalgesia (DAMGOX3, DAMGO/PGE $2, p=N S, n=12$ ). However, unlike in the naive rats, $\mathrm{PGE}_{2}$ hyperalgesia was still present at fourth hour in the DAMG0x3-pretreated rats (DAMGOX3, fourth hour DAMGO/PGE, $n<0.001, n=12$ ). After three hourly injections of DAMGO, $\mathrm{PGE}_{2}$ alone also produced prolonged $\left(>4\right.$ h) hyperalgesia (DAMGOX3, PGE $_{2},{ }^{\ddagger} p<0.001, n=6$ ). The tolerance to DAMGO inhibition of $\mathrm{PGE}_{2}$ hyperalgesia and prolongation of $\mathrm{PGE}_{2}$ hyperalgesia was still observed $5 \mathrm{~d}$ after 3 hourly doses of DAMGO (DAMGOx3, day 5, DAMGO/PGE 2 , both ${ }^{\#} p<$ $0.001, n=6)$. In all experiments, measurement of paw withdrawal threshold was done at $30 \mathrm{~min}\left(30^{\prime}\right)$ and $4 \mathrm{~h}(4 \mathrm{~h})$ after the administration of the test agents.

Biochemicals, pseudo receptor octapeptide for activated PKC $\varepsilon(\psi \varepsilon$ RACK; a specific agonist of PKC $\varepsilon$ ) from SynPep Corp., D-Phe-Cys-Tyr-D-Trp-OrnThr-Pen-Thr- $\mathrm{NH}_{2}$ (CTOP), a potent and highly selective $\mu$-opioid receptor antagonist (Tocris Bioscience), and EAVSLKPT (PKC $\varepsilon_{\mathrm{V} 1-2}$, a selective PKC $\varepsilon$ translocation inhibitor peptide, EMD Bioscience). The selection of the drug doses used in this study was based on dose-response curves determined in previously published studies (Aley and Levine, 1997; Aley et al., 2000; Liu and Anand, 2001; Joseph and Levine, 2004; Joseph et al., 2004, 2008). The stock solution of $\mathrm{PGE}_{2}(10 \mu \mathrm{g} / \mu \mathrm{l})$ was prepared in ethanol, and further dilutions made in saline, yielding a final ethanol concentration of $<1 \%$. All other drugs were dissolved in saline. All drugs administered intradermally were in a volume of $5 \mu \mathrm{l}$ using a 30 -gauge hypodermic needle attached to a $10 \mu \mathrm{l}$ Hamilton syringe, except carrageenan, which because of its high viscosity, was injected using a 27 -gauge needle. When an antagonist was included, it was injected either 30 min before the agonist or coinjected with the agonist. When drug combinations were coinjected, they were administered from the same syringe so that the drug listed first, reached the intradermal site first.

Antisense and mismatch oligodeoxynucleotide. Oligodeoxynucleotide $(\mathrm{ODN})$ antisense and mismatch to $\mathrm{PKC} \varepsilon$ were prepared as described previously (Parada et al., 2003; Dina et al., 2006). The antisense ODN, 5'-GCC AGC TCG ATC TTG CGC CC-3', was directed against a unique sequence of rat PKC $\varepsilon$. The corresponding GenBank (National Institutes of Health, Bethesda, MD) accession number and ODN position within the cDNA sequence are XM345631 and 226-245, respectively. We have previously shown that spinal intrathecal administration of antisense ODN with this sequence decreases PKCe protein in dorsal root ganglia (Parada et al., 2003). The sequence of the mismatch ODN, 5'-GCC AGC GCG ATC TTT CGC CC- ${ }^{\prime}$, corresponds to the PKC $\varepsilon$ antisense sequence with 2 bases mismatched (in bold typeface). Control animals received injections of mismatch ODN.

Before use, lyophilized ODN was reconstituted in nuclease-free $0.9 \%$ $\mathrm{NaCl}$ to a concentration of $5 \mu \mathrm{g} / \mu \mathrm{l}$ and stored at $-20^{\circ} \mathrm{C}$ until use. A dose of $20 \mu \mathrm{g}$ of antisense or mismatch ODN was intrathecally administered in a volume of $20 \mu \mathrm{l}$ once daily for $3 \mathrm{~d}$. Before each injection, rats were anesthetized with $2.5 \%$ isoflurane containing oxygen. ODN was injected using a 30-gauge needle inserted between the fifth and sixth lumbar vertebrae, at the level of the cauda equina.

Protocol to induce opioid tolerance. $\mathrm{PGE}_{2}$ induces dose-dependent mechanical hyperalgesia when injected intradermally in the dorsum of the rat's hindpaw (Khasar et al., 1994; Parada et al., 2003). A single dose of DAMGO $(1 \mu \mathrm{g})$, a $\mu$-opioid receptor agonist, attenuated $\mathrm{PGE}_{2}$ (100 ng)-induced hyperalgesia when injected with $\mathrm{PGE}_{2}$ (Aley et al., 1995; Aley and Levine, 1997). However, 3 hourly injections of DAMGO produced tolerance to the antinociceptive effect of a fourth hourly injection (Aley and Levine, 1997). This protocol of 3 hourly administrations of DAMGO was employed in all opioid tolerance experiments.

Protocol to detect opioid dependence. The selective $\mu$-opioid receptor antagonist CTOP, which had no effect on the paw withdrawal threshold of normal rats, produced withdrawal hyperalgesia when administered on the fourth hour following 3 hourly injections of DAMGO (Aley and Levine, 1997). This protocol was used, throughout this study, to test for opioid dependence.

Statistical analysis. Group data are presented as mean \pm SEM of $n=6$ or more observations in each experimental group. Statistical significance was determined by ANOVA followed by Scheffe's post hoc test; $p<0.05$ was considered statistically significant.

\section{Results \\ Hyperalgesic priming induced by a $\boldsymbol{\mu}$-opioid agonist}

As previously reported (Aley and Levine, 1997), the intradermal coinjection of DAMGO $(1 \mu \mathrm{g})$ with $\mathrm{PGE}_{2}(100 \mathrm{ng})$ in the hindpaw of naive rats inhibits the mechanical hyperalgesia induced by the $\mathrm{PGE}_{2}$ (Fig. 1). However, when the coadministration of DAMGO and $\mathrm{PGE}_{2}$ was performed $1 \mathrm{~h}$ after 3 hourly injections of DAMGO, the DAMGO was no longer able to attenuate $\mathrm{PGE}_{2}$ hyperalgesia (Fig. 1). In addition to this opioid tolerance, the 3 injections of DAMGO induced hyperalgesic priming. Thus, while $\mathrm{PGE}_{2}$ hyperalgesia is short-lived $(<4 \mathrm{~h})$ in naive control rats, it is markedly prolonged in rats pretreated with 3 hourly injections of DAMGO, persisting unattenuated for at least $4 \mathrm{~h}$, even when DAMGO is coinjected with $\mathrm{PGE}_{2}$.

In a previous study (Aley et al., 1995), control experiments in which saline was injected in the same $3 \times$ hourly protocol showed no significant effect of the DAMGO vehicle on nociceptive threshold. In the present study, baseline nociceptive threshold was not significantly different between any of the experimental groups.

Hyperalgesic priming induced by DAMGO persists, similar to the long-lived priming induced by carrageenan (Parada et al., 2005), with $\mathrm{PGE}_{2}$ hyperalgesia still enhanced when tested $4-5 \mathrm{~d}$ after 3 hourly injections of DAMGO (Fig. 1). Of note, while hyperalgesic priming induced by carrageenan (or even by the PKC $\varepsilon$ activator $\psi \varepsilon$ RACK) requires 3-5 d to develop (Aley et al., 2000), that induced by 3 hourly injections of DAMGO is already present by $1 \mathrm{~h}$ after the last dose of DAMGO.

We have previously shown that the development of inflammation-induced hyperalgesic priming is PKC $\varepsilon$-dependent (Aley et al., 2000). Therefore, we next determined whether the development of DAMGO-induced hyperalgesic priming is also $\mathrm{PKC} \varepsilon$-dependent. Spinal intrathecal administration of ODN antisense to $\mathrm{PKC} \varepsilon$, was used in a protocol $(20 \mu \mathrm{g}$ in a volume of 20 $\mu \mathrm{l}$ daily, for $3 \mathrm{~d}$ ) shown previously to decrease PKC $\varepsilon$ expression and function in primary afferent nociceptors and to prevent carrageenan-induced hyperalgesic priming (Parada et al., 2003; 

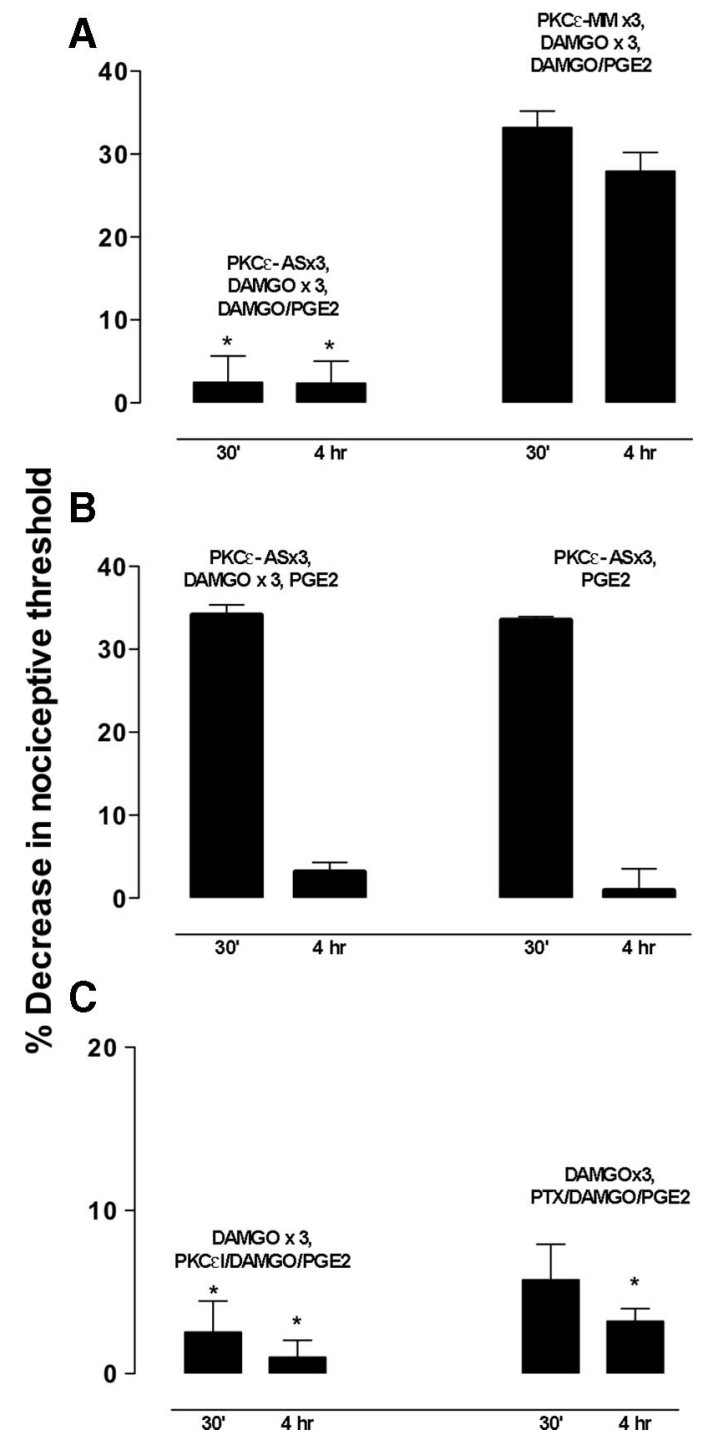

Figure 2. A, Spinal intrathecal injection of oligodeoxynucleotide (ODN) antisense (PKC $\varepsilon$-AS) but not mismatch (PKC $\varepsilon$-MM) for PKC $\varepsilon$ (20 $\mu$ g in a volume of $20 \mu$ l, i.t.), daily for $3 \mathrm{~d}$, prevented the development of tolerance and priming when on the fourth day 3 hourly injections of DAMG0 $\times 3$ was followed at the fourth hour by DAMG0 plus $\mathrm{PGE}_{2}(\mathrm{PKC} \varepsilon-\mathrm{AS} \times 3, \mathrm{DAMGO} \times 3$, DAMGO/PGE $2,{ }^{*} p<0.001$ compared with naive, $n=6$ and PKC $\varepsilon$-MMX3, DAMG0x3, DAMG0/ $\mathrm{PGE}_{2}, p=\mathrm{NS}$ compared with naive, $\left.n=6\right)$. $\boldsymbol{B}$, Spinal intrathecal injection of PKC $\varepsilon$-AS for $3 \mathrm{~d}$ prevented priming (hyperalgesia at the fourth hour), when on the fourth day whether $\mathrm{PGE}_{2}$ was injected with DAMG0, following 3 hourly injections of DAMGO (PKC $\varepsilon$-ASx3, DAMG0×3, PGE $p=\mathrm{NS}, n=6)$, or injected without DAMGO (PKC $\left.\varepsilon-\mathrm{ASX}_{3}, \mathrm{PGE}_{2}, p=\mathrm{NS}, n=6\right)$; in both groups $\mathrm{PGE} 2$ hyperalgesia at 30 min was not affected. $C$, Intradermal injection of $\mathrm{PKC} \varepsilon_{\mathrm{V1}-2,}$ a selective PKC $\varepsilon$ translocation inhibitor peptide (PKC $\varepsilon 1,1 \mu \mathrm{g}$ ), or pertussis toxin (PTX, $10 \mathrm{ng}$ ), a G - protein inhibitor, reversed (DAMG0x3-induced) tolerance and priming when injected $30 \mathrm{~min}\left(30^{\prime}\right)$

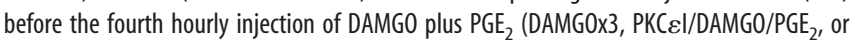
DAMG0x3, PTX/DAMGO/PGE 2 , both ${ }^{*} p<0.001, n=6 /$ group).

Joseph et al., 2007). One day after the third and last injection of antisense or mismatch ODN, three hourly injections of DAMGO were administered, followed at the fourth hour by DAMGO plus $\mathrm{PGE}_{2}$. The PKC $\varepsilon$-antisense ODN pretreatment prevented the development of DAMGO-induced hyperalgesic priming (the hyperalgesia induced by $\mathrm{PGE}_{2}$ was not enhanced or prolonged compared with that in mismatch ODN-treated rats) (Fig. 2A,B). $\mathrm{PKC} \varepsilon$-antisense ODN also restored the ability of DAMGO to inhibit $\mathrm{PGE}_{2}$ hyperalgesia in rats treated with three hourly injections of DAMGO (DAMGOx3-treated rats) (Fig. $2 A, B$ ). To con- firm that $\mathrm{PGE}_{2}$-induced hyperalgesia was not attenuated by PKC $\varepsilon$ antisense, separate groups of rats were treated with antisense for $3 \mathrm{~d}$ and $\mathrm{PGE}_{2}$ was administered on the fourth day following three hourly injections of DAMGO or without prior treatment with DAMGO. $\mathrm{PGE}_{2}$ hyperalgesia was not attenuated by prior antisense treatment (Fig. $2 B$ ). The role of PKC $\varepsilon$ was confirmed using an alternative method of reducing $\mathrm{PKC} \varepsilon$ activity, intradermal injection of the PKC $\varepsilon$ antagonist, $\mathrm{PKC} \varepsilon_{\mathrm{V} 1-2}$ (1 $\mu \mathrm{g}$ ) (Fig. $2 C$ ). In inflammation-induced hyperalgesic priming, there is a switch in the G-protein specie that mediates $\mathrm{PGE}_{2}$ induced hyperalgesia, from $G_{s}$ to $G_{i}$, as indicated by the development of sensitivity to inhibition by pertussis toxin (Dina et al., 2009). We found that pertussis toxin (10 $\mathrm{ng}$ ) also attenuates $\mathrm{PGE}_{2}$-induced hyperalgesia in DAMGO-primed rats (Fig. 2C).

\section{$\boldsymbol{\mu}$-Opioid tolerance induced by inflammation}

Having determined that the induction of $\mu$-opioid tolerance also produces hyperalgesic priming, we next tested whether, conversely, $\mu$-opioid tolerance is produced when intradermal injection of carrageenan or a direct activator of PKC $\varepsilon, \psi \varepsilon$ RACK, induces hyperalgesic priming. Injection of carrageenan $(5 \mu \mathrm{l}$ of a $1 \%$ solution) or $\psi \varepsilon$ RACK $(1 \mu \mathrm{g})$ produced hyperalgesia that lasted $\sim 3 \mathrm{~d}$ (data not shown). On day 5 following injection of carrageenan or $\psi \varepsilon$ RACK, when nociceptive threshold had returned to pretreatment baseline, DAMGO did not inhibit $\mathrm{PGE}_{2}$ hyperalgesia (Fig. 3A). However, administration of ODN antisense, but not mismatch, to $\mathrm{PKC} \varepsilon$, for $3 \mathrm{~d}$ before injection of carrageenan or $\psi \varepsilon$ RACK, blocked the development of tolerance for inhibition of $\mathrm{PGE}_{2}$ hyperalgesia by DAMGO, even when measured $5 \mathrm{~d}$ after administration of carrageenan or $\psi \varepsilon$ RACK (Fig. $3 B$ ). Tolerance to the analgesic effect of the potent $\mu$-opioid agonist DAMGO, induced by intradermal injection of carrageenan and $\psi \varepsilon$ RACK, was also attenuated by intradermal injection of the $\mathrm{PKC} \varepsilon$ antagonist, $\mathrm{PKC} \varepsilon_{\mathrm{V} 1-2}$ (Fig. $3 C$ ), and the $\mathrm{G}_{\mathrm{i}}$-protein inhibitor, pertussis toxin (Fig. 3D), demonstrating a role for PKC $\varepsilon$ and $G_{i}$ in the peripheral terminals of the primary afferent nociceptor.

\section{$\mu$-Opioid dependence induced by inflammation: PKC $\varepsilon$} and $G_{i}$ mediation of opioid withdrawal hyperalgesia

We have previously shown that the protocol of 3 hourly intradermal injections of DAMGO, also induces $\mu$-opioid receptor dependence, demonstrated by the ability of the $\mu$-opioid receptor antagonist, CTOP $(1 \mu \mathrm{g})$, to induce mechanical hyperalgesia (Aley et al., 1995). In the present study we found that this CTOPinduced hyperalgesia (Fig. $4 A$ ) was inhibited by the PKC $\varepsilon$ antagonist, $\mathrm{PKC} \varepsilon_{\mathrm{V} 1-2}$, and by the $\mathrm{G}_{\mathrm{I}}$ inhibitor, pertussis toxin (Fig. $4 A)$. Furthermore, we found that hyperalgesic priming induced by either carrageenan or $\psi \varepsilon$ RACK (which induce $\mu$-opioid tolerance) also induced $\mu$-opioid dependence (Fig. $4 B, C$ ). CTOP was injected $5 \mathrm{~d}$ after carrageenan or $\psi \varepsilon \mathrm{RACK}$ administration, when nociceptive threshold had returned to baseline. In both groups of rats (neither of which had been exposed to $\mu$-opioid agonist) CTOP induced mechanical hyperalgesia (Fig. $4 B, C$ ). The PKC $\varepsilon$ antagonist $\mathrm{PKC} \varepsilon_{\mathrm{V} 1-2}$ and the $\mathrm{G}_{\mathrm{i}}$-protein inhibitor pertussis toxin also attenuated this hyperalgesia (Fig. $4 B, C$ ).

\section{Discussion}

We demonstrate that repeated administration of a $\mu$-opioid agonist, DAMGO to produce tolerance and dependence to the peripheral analgesic action of the opioid produces hyperalgesic priming, and conversely, that induction of hyperalgesic priming by inflammation produces opioid tolerance and dependence. Furthermore, both effects are produced via PKC $\varepsilon$-dependent 

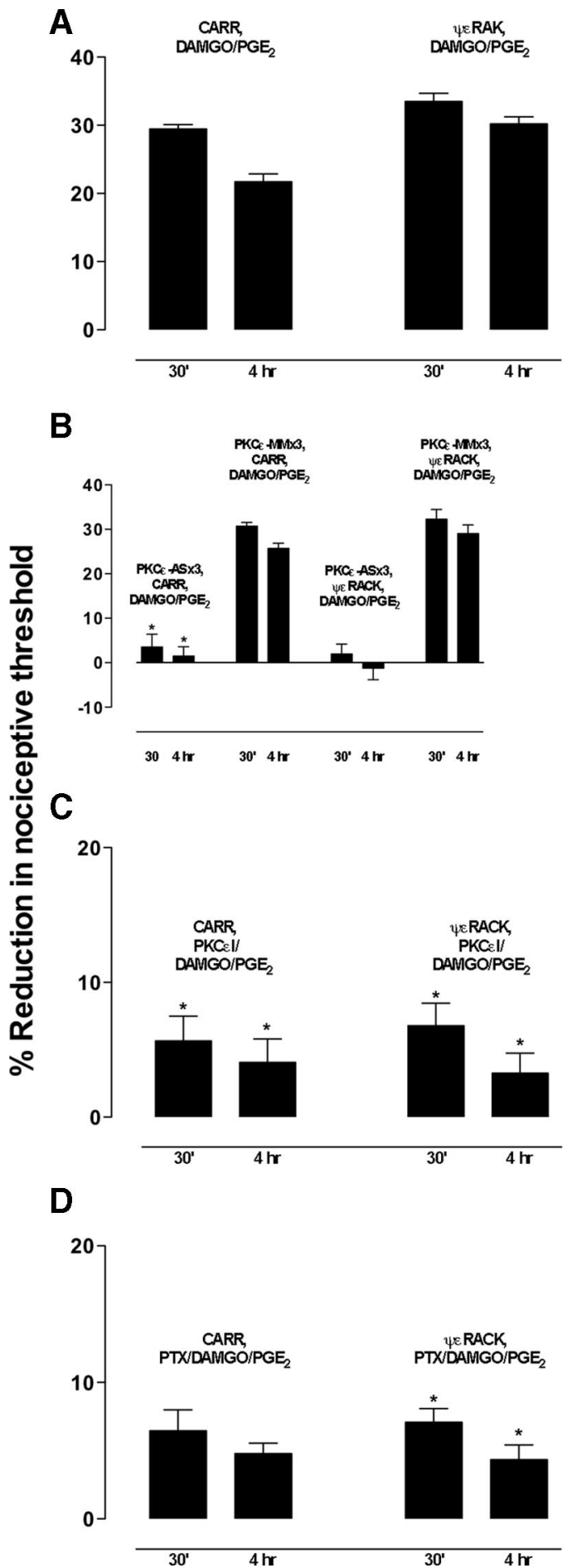

Figure 3. $A, D A M G 0$ did not attenuate $\mathrm{PGE}_{2}$-induced hyperalgesia in carrageenan (CARR, 5 $\mu$ of $1 \%$ solution)- or protein kinase $(\varepsilon$ activator ( $\psi \varepsilon R A C K, 1 \mu \mathrm{g})$-pretreated ( $5 \mathrm{~d}$ prior) rats (CARR, fifth day DAMGO/PGE ${ }_{2}, p=\mathrm{NS}, n=6 ; \psi \varepsilon$ RACK, fifth day DAMGO/PGE $2, p=\mathrm{NS}, n=$ 6). $P E_{2}$ hyperalgesia was still present at the fourth hour in the CARR- and $\psi \varepsilon$ RACK-pretreated rats. $B$, Spinal intrathecal injection of antisense (PKC $\varepsilon$-AS) but not mismatch (PKC $\varepsilon$-MM) ODN for PKC $\varepsilon(20 \mu \mathrm{g}$ in a volume of $20 \mu \mathrm{l})$, for threed, prevented the development of tolerance and priming when CARR or $\psi \varepsilon R A C K$ were injected on the fourth day and the effect of DAMGO on $\mathrm{PGE}_{2}$ hyperalgesia was tested $5 \mathrm{~d}$ after the administration of CARR or $\psi \varepsilon$ RACK. (PKC $\varepsilon-\mathrm{AS} \times 3$, CARR, DAMGO/PGE 2 and PKC $\varepsilon$-ASX3, $\psi \varepsilon R A C K$, DAMGO/PGE 2 , both ${ }^{*} p<0.001, n=6 /$ group; $\mathrm{PKC} \varepsilon-\mathrm{MM} \times 3, \mathrm{CARR}, \mathrm{DAMGO} / \mathrm{PGE} \mathrm{E}_{2}$ and PKC $\varepsilon-\mathrm{MM} \times 3, \psi \varepsilon \mathrm{RACK}, \mathrm{DAMGO} / \mathrm{PGE}_{2}$, both $p=\mathrm{NS}$, $n=6 /$ group). $C$, Intradermal injection of $\mathrm{PKC}_{\varepsilon V 1-2,}$ a selective PKC $\varepsilon$ translocation inhibitor peptide (PKC $\varepsilon 1,1 \mu \mathrm{g})$, also reversed tolerance and priming when PKC $\varepsilon$ l was injected 30 $\min \left(30^{\prime}\right)$ before DAMGO/PGE 2 on the fifth day following the administration of CARR or $\psi \varepsilon$ RACK (CARR, PKC $\varepsilon$ I/DAMG0/PGE 2 and $\psi \varepsilon$ RACK, PKC $\varepsilon$ I/DAMGO/PGE 2 , both ${ }^{*} p<0.001$,

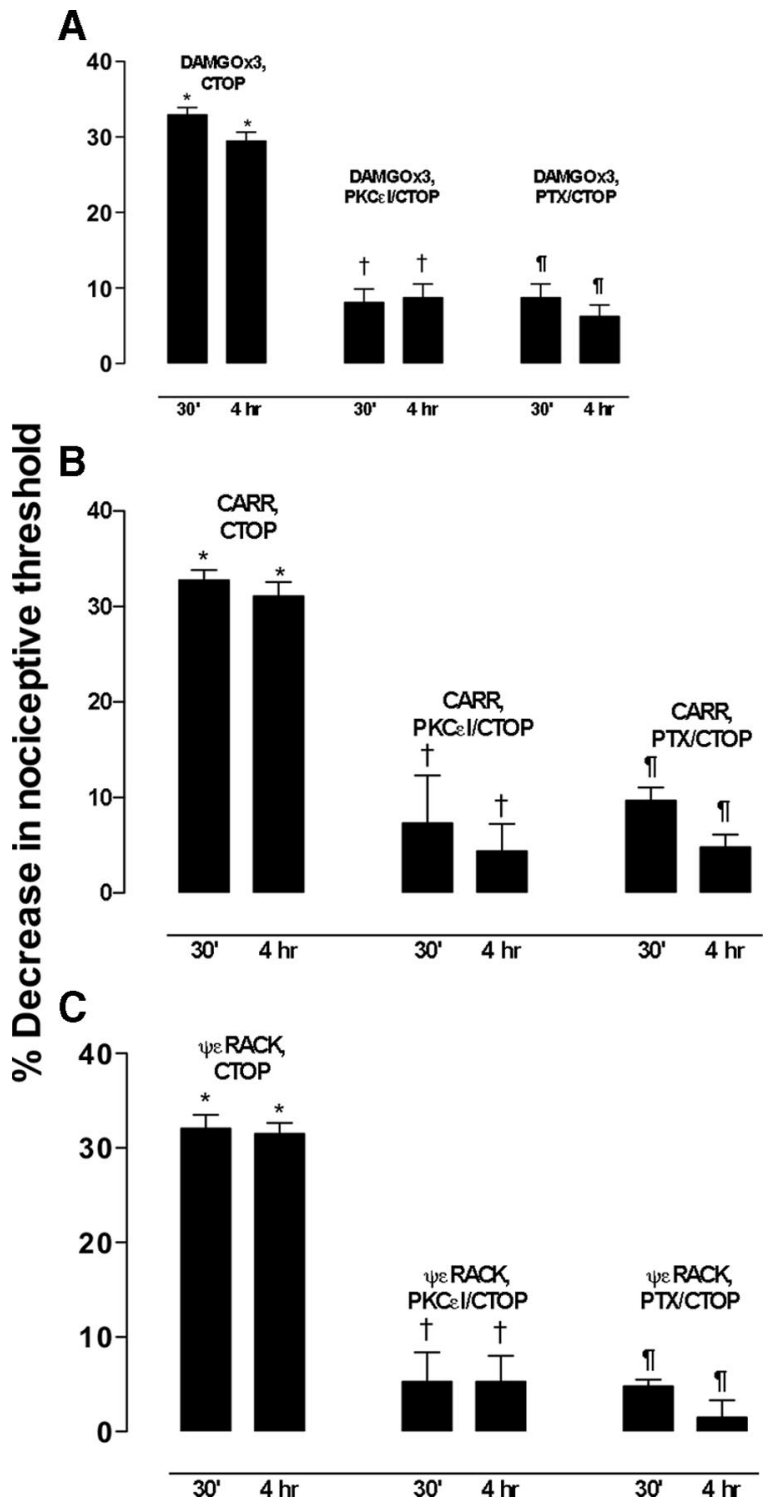

Figure 4. A, Intradermal injection of CTOP $(1 \mu \mathrm{g})$, a selective $\mu$-opioid antagonist, at the fourth hour following three hourly injections of DAMGO produced hyperalgesia (DAMG0x3, CTOP, ${ }^{*} p<$ 0.001 compared with baseline, $n=6$ ) and this hyperalgesia was still present at the fourth hour after CTOP administration. Injection of PKC $\varepsilon$ inhibitor (PKC $\varepsilon_{\varepsilon V 1-2}$ ) or the $\mathrm{G}_{\mathrm{i}}$-protein inhibitor PTX 30 min $\left(30^{\prime}\right.$ ) before CTOP reversed CTOP hyperalgesia (DAMGOX3, PKCEl/CTOP, ${ }^{\dagger} p<0.001, n=6$; DAMGOX3, PTX/CTOP, " $p<0.001, n=6$ ). $\boldsymbol{B}$, Intradermal injection of (TOP in CARR-pretreated rats ( 5 d prior) produced significant hyperalgesia (CARR, fifth day, $C$ TOP, ${ }^{*} p<0.001, n=6$ ). Injection of $\mathrm{PKC}_{\varepsilon \mathrm{V1}-2}$ or PTX $30 \mathrm{~min}\left(30^{\prime}\right)$ before CTOP reversed CTOP hyperalgesia (CARR, PKC $\varepsilon \mathrm{El} / \mathrm{CTOP},{ }^{\dagger} p<$ $0.001, n=6$; CARR, PTX/CTOP, " $p<0.001, n=6$ ). C, Intradermal injection of (TOP in $\psi \varepsilon$ RACKpretreated rats ( $5 \mathrm{~d}$ prior) produced significant hyperalgesia ( $\psi \varepsilon$ RACK, fifth day, $\left(T O P,{ }^{*} p<0.001\right.$, $n=6)$. Injection of $\mathrm{PKC}_{\varepsilon V 1-2}$ or the PTX $30 \mathrm{~min}\left(30^{\prime}\right)$ before (TOP reversed (TOP hyperalgesia ( $\psi \varepsilon \varepsilon \mathrm{RACK}, \mathrm{PKC} \varepsilon \mathrm{I} / \mathrm{CTOP},{ }^{+} p<0.001, n=6 ; \psi \varepsilon \mathrm{RACK}, \mathrm{PTX} /\left(\mathrm{CTOP},{ }^{"} p<0.001, n=6\right.$ ).

mechanisms in primary afferents. These findings suggest that both the transition from persistent acute pain to a chronic pain state and the loss of responsiveness to opioid analgesics result from a single PKC $\varepsilon$-dependent neuroplastic change in the primary

$\leftarrow$

$n=6 /$ group). $\boldsymbol{D}$, Intradermal injection of pertussis toxin, a $G_{i}$ inhibitor (PTX, $\left.10 \mathrm{ng}\right)$, also reversed tolerance and priming when it was injected $30 \mathrm{~min}\left(30^{\prime}\right)$ before $\mathrm{DAMGO} \mathrm{PGE}_{2}$ on the fifth day following the administration of CARR or $\psi \varepsilon \varepsilon$ RACK (CARR, PTX/DAMGO/PGE 2 and $\psi \varepsilon$ RACK, PTX/DAMGO/PGE 2 , both ${ }^{*} p<0.001, n=6 /$ group). 
afferent nociceptor. This idea is compatible with the common clinical observation that a critical transition occurs in patients when opioid-sensitive "persistent acute pain" transforms into an opioid-resistant "chronic pain" state. Reversal of neuroplastic changes associated with hyperalgesic priming might provide a new therapeutic strategy for reinstating sensitivity to opioid analgesics in patients suffering from intractable chronic pain.

The mechanistic interactions between the transition to chronic pain and the development of resistance to opioid analgesics at the level of the peripheral terminal of the primary afferent nociceptor may play a role in other clinically observed interactions between opioids and chronic pain that are otherwise difficult to explain (Fig. 5). For example, chronic use of opioid analgesics can contribute to the transition from acute intermittent pain to chronic pain in patients with migraine and other types of headache (Mathew et al., 1982; Wilkinson et al., 2001; Biondi, 2003; Bigal and Lipton, 2009) and may also contribute to the "chronification" of low back (Webster et al., 2007; Franklin et al., 2008), and other pain conditions (Compton, 1994; Mao et al., 1995; Savage, 1996). Chronic opioid use can also produce or enhance ongoing pain, a phenomenon referred to as "opioidinduced hyperalgesia" (Mercadante and Arcuri, 2005; Chu et al., 2008; Chen et al., 2009; Hay et al., 2009). Although opioid-induced hyperalgesia was not observed in the present study, we hypothesize that opioidinduced hyperalgesia may originate in part from $\mathrm{PKC} \varepsilon$-dependent mechanisms (Chu et al., 2008) related to those that mediate hyperalgesic priming and opioid tolerance/dependence.

We found that the $\mu$-receptor antagonist CTOP reduced the hyperalgesic priming that followed a series of injections of the $\mu$-receptor agonist DAMGO. One potential explanation for this observation is that CTOP antagonized an action of residual DAMGO remaining at the injection site. This seems unlikely, however, in view of the very small amount of DAMGO injected (1 $\mu \mathrm{g})$ and because the enhancement of nociception is not observed when a $\mu$ receptor antagonist is injected with DAMGO (upon first injection of DAMGO in an opioid-naive animal) (Aley et al., 1995). Of note in this regard, the literature on opioid tolerance describes a mechanism by which opiate analgesics can produce a change in the response to CTOP that outlasts the presence of opiate. Thus, exposure to $\mu$-agonists (including DAMGO) can transform the $\mu$-opioid receptor into an agonist-independent constitutively active state (Liu and Prather, 2001), revealing an inverse agonist action of CTOP (Brillet et al., 2003). We speculate that such constitutive $\mu$-receptor activity occurs in hyperalgesic priming, and accounts for our observations with CTOP. The constitutive activity might be induced either by the exogenous DAMGO or, when carrageenan is the priming agent, by inflammogen stimulated release of endogenous opioids during the $3 \mathrm{~d}$ of carrageenan-induced hyperalgesia (Wang et al., 2004).
B
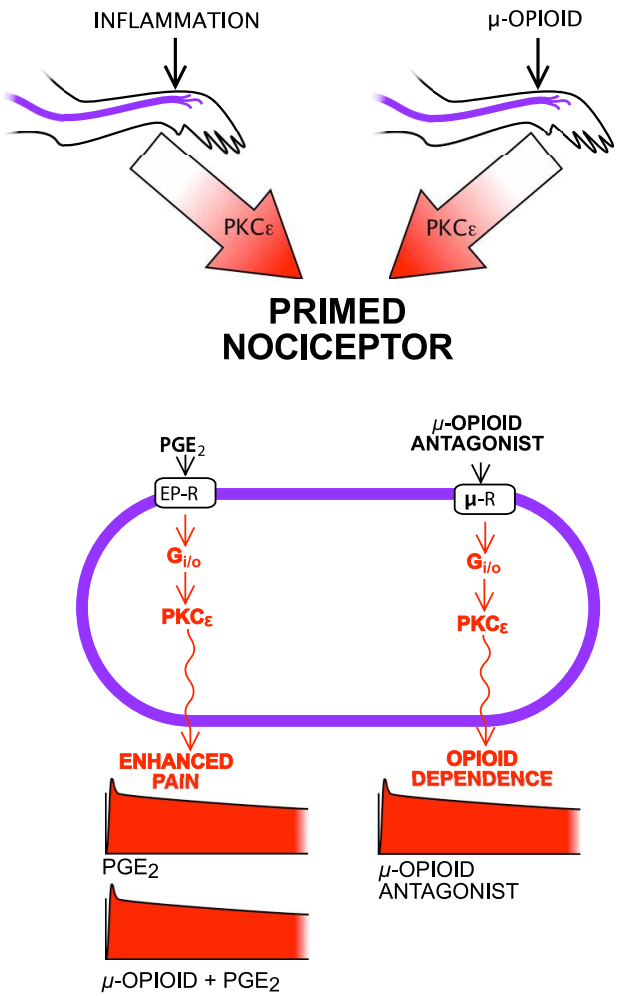

Figure 5. A proposed mechanism relating the transition to chronic pain and the loss of analgesic efficacy. $\boldsymbol{A}$, In a nociceptor (purple) in the hindpaw of a naive animal, a proinflammatory cytokine ( $\left.\mathrm{PGE}_{2}\right)$, causes acute pain (hyperalgesia lasting $<4 \mathrm{~h}$ ) that is mediated by activation of a $\mathrm{G}_{s}$-protein-coupled receptor for prostaglandin (EP-R) causing increased adenylyl cyclase (AC) activity a produce prolonged hyperalgesia, a model of chronic pain and opioid tolerance and dependence.

The known cellular mechanisms of hyperalgesic priming are similar (PKC $\varepsilon$ dependence and G-protein switch in cytokine hyeralgesia), whether the priming is induced by an inflammogen, a direct PKC $\varepsilon$ activator, a $\mu$-opioid agonist, or stress. However, priming induced by the $\mu$-opioid DAMGO differs in one notable respect; opioid-induced priming develops in $<4 \mathrm{~h}$, while that induced by inflammation requires 3-5 d (Aley et al., 2000) and that by sound stress, 1-2 weeks (Khasar et al., 2008). Such rapid onset of opioid-induced hyperalgesic priming may provide important insights for future investigation of the PKC $\varepsilon$-dependent pathways that mediate hyperalgesic priming. Thus, mechanisms such as transcription and translation, which would seem compatible with the longer time course of hyperalgesic priming induced by inflammation or stress seem much less feasible in the underfour-hour timeframe of opioid-induced priming. This suggests the possibility that opioids induce priming by engaging a cellular mechanism downstream to that engaged by the other inducers of hyperalgesic priming that we have investigated.

Our finding of opioid-induced hyperalgesic priming also provides some insight into mechanisms underlying the prolonged hyperalgesia induced by $\mathrm{PGE}_{2}$. While we have previously shown that the hyperalgesia induced by $\mathrm{PGE}_{2}$, following induction of hyperalgesic priming remains protein kinase A dependent (Aley et al., 2000), the present finding that pertussis toxin inhibits $\mathrm{PGE}_{2}$ hyperalgesia at the $30 \mathrm{~min}$ time point indicates that in the primed state this PKA-dependent hyperalgesia is $G_{i}$, not $G_{s}$, dependent. 
We have recently demonstrated that chronic unpredictable stress also produces hyperalgesic priming in the primary afferent (Khasar et al., 2008; Dina et al., 2009). Because stress-induced hyperalgesic priming exhibited PKC $\varepsilon$ dependence similar to the $\mathrm{PKC} \varepsilon$ dependence that we now know is shared by inflammationinduced and opioid-induced priming, we predict that interactions among stress, inflammation, and opioids at the level of primary afferent intracellular signaling pathways may contribute to the generation of opioid-resistant chronic pain states. Consistent with this idea, stress-induced analgesia can be cross-tolerant with morphine-induced analgesia (Lewis et al., 1981; Girardot and Holloway, 1984; Szikszay and Benedek, 1989; da Silva Torres et al., 2003; Fazli-Tabaei et al., 2005). Thus, interaction among stress, opioids and hyperalgesic priming at the level of the primary afferent nerve ending may be important in pain patients in which all three factors often coexist.

It is likely that the cell signaling interactions between different inducers of hyperalgesic priming are not limited only to PKC $\varepsilon$ and G-protein switching. For example, phospholipase $C \beta 3$ (PLC $\beta 3$ ) also contributes to inflammatory mediator-induced mechanical hyperalgesia and $\mu$-opioid analgesia. Specifically, we and others have demonstrated the presence of PLC $\beta 3$ in smalldiameter dorsal root ganglion neurons (Han et al., 2006; Joseph et al., 2007; Shi et al., 2008), and provided evidence that it is upstream of PKC $\varepsilon$ in nociceptor sensitization and hyperalgesic priming (Joseph et al., 2007). $\mu$-opioid agonists have also been shown to activate PLC (Ono et al., 2002; Galeotti et al., 2006; Mathews et al., 2008), by releasing $\beta / \gamma$ subunits from Gi $\alpha_{2 / \mathrm{o}}$ (Murthy and Makhlouf, 1996; Xie et al., 1999; Bianchi et al., 2009), which in turn might contribute to the paradoxical hyperalgesia induced by chronic opioid administration (Rosenblum et al., 2008). PLC $\beta 3$ also contributes to $\mu$-opioid tolerance and dependence (Mestek et al., 1995; Smith et al., 1999; Rosenblum et al., 2008). While PLC $\beta 3$ has been shown to be a downstream target of the cAMP-activated guanine exchange factor, Epac (Hucho et al., 2005), the exact relationship of the PLC $\beta 3$ contribution to those of PKC $\varepsilon$ and $\mathrm{G}_{\mathrm{i}}$-proteins, in the transition to chronic pain and $\mu$-opioid receptor tolerance and dependence remains to be established.

Our findings in the peripheral nervous system may also have relevance to interactions between chronic pain and opioid analgesics in the CNS. Thus, $\mu$-opioid receptors are also located on the central terminals of primary afferents in the spinal cord and trigeminal dorsal horn (Kline and Wiley, 2008) where they contribute to the analgesic effect of systemically administered opioids (Aicher et al., 2000; Kohno et al., 2005). There is abundant evidence for PKC signaling and G-protein switching in opioid tolerance and dependence at spinal and supraspinal sites (Mestek et al., 1995; Liu and Anand, 2001; Sánchez-Blázquezet al., 2001; Chakrabarti et al., 2005; Wang and Burns, 2006; Kelly et al., 2008). Similarly, in PKCe knock-out mice, systemic opioids induce both enhanced analgesia and decreased opioid tolerance (Newton et al., 2007). Furthermore, morphine has been shown to induce rapid and marked desensitization of $\mu$-opioid receptors in locus ceruleus neurons, but only when protein kinase $\mathrm{C}$ is activated (Bailey et al., 2004).

Any potential role that hyperalgesic priming might play in the CNS would be in addition to other well documented central mechanisms likely to play a role in the opioid-resistance that characterizes chronic pain states. For example, opioid activation of astrocytes and microglia in the CNS may play an important role in neuropathic pain and opioid tolerance (Watkins et al., 2009). (In contrast, it seems unlikely that a similar effect of opi- oids on the sparse glial cells in the skin could play an important role in the peripheral effects we have described.) Another important mechanism of interactions between opiate use and chronic pain in the CNS is pain-related increases in expression of cholecystokinin (the "anti-opioid") that can antagonize opiate analgesia (Wiesenfeld-Hallin et al., 2002).

In conclusion, the present experiments demonstrate shared mechanisms between a transition from acute to chronic pain and the development of $\mu$-opioid tolerance and dependence. These observations provide insight into possible cellular mechanisms of the opioid-resistance that characterizes many chronic pain states, as well as clues toward possible avenues in our search for novel approaches to address the great suffering and societal expense caused by intractable chronic pain.

\section{References}

Aicher SA, Punnoose A, Goldberg A (2000) mu-Opioid receptors often colocalize with the substance $\mathrm{P}$ receptor $(\mathrm{NK} 1)$ in the trigeminal dorsal horn. J Neurosci 20:4345-4354.

Aley KO, Levine JD (1997) Multiple receptors involved in peripheral alpha 2, mu, and A1 antinociception, tolerance, and withdrawal. J Neurosci 17:735-744.

Aley KO, Green PG, Levine JD (1995) Opioid and adenosine peripheral antinociception are subject to tolerance and withdrawal. J Neurosci 15:8031-8038.

Aley KO, Messing RO, Mochly-Rosen D, Levine JD (2000) Chronic hypersensitivity for inflammatory nociceptor sensitization mediated by the epsilon isozyme of protein kinase C. J Neurosci 20:4680-4685.

Bailey CP, Kelly E, Henderson G (2004) Protein kinase C activation enhances morphine-induced rapid desensitization of mu-opioid receptors in mature rat locus ceruleus neurons. Mol Pharmacol 66:1592-1598.

Bianchi E, Lehmann D, Vivoli E, Norcini M, Ghelardini C (2009) Involvement of PLC-\{beta\} 3 in the effect of morphine on memory retrieval in passive avoidance task. J Psychopharmacol. Advance online publication. Retrieved May 15, 2009. doi:10.1177/0269881108102013.

Bigal ME, Lipton RB (2009) Overuse of acute migraine medications and migraine chronification. Curr Pain Headache Rep 13:301-307.

Biondi DM (2003) Opioid resistance in chronic daily headache: a synthesis of ideas from the bench and bedside. Curr Pain Headache Rep 7:67-75.

Brillet K, Kieffer BL, Massotte D (2003) Enhanced spontaneous activity of the mu opioid receptor by cysteine mutations: characterization of a tool for inverse agonist screening. BMC Pharmacol 3:14.

Chakrabarti S, Regec A, Gintzler AR (2005) Biochemical demonstration of mu-opioid receptor association with Gsalpha: enhancement following morphine exposure. Brain Res Mol Brain Res 135:217-224.

Chen L, Malarick C, Seefeld L, Wang S, Houghton M, Mao J (2009) Altered quantitative sensory testing outcome in subjects with opioid therapy. Pain 143:65-70.

Chu LF, Angst MS, Clark D (2008) Opioid-induced hyperalgesia in humans: molecular mechanisms and clinical considerations. Clin J Pain 24:479-496.

Compton MA (1994) Cold-pressor pain tolerance in opiate and cocaine abusers: correlates of drug type and use status. J Pain Symptom Manage 9:462-473.

da Silva Torres IL, Cucco SN, Bassani M, Duarte MS, Silveira PP, Vasconcellos AP, Tabajara AS, Dantas G, Fontella FU, Dalmaz C, Ferreira MB (2003) Long-lasting delayed hyperalgesia after chronic restraint stress in rats-effect of morphine administration. Neurosci Res 45:277-283.

Dina OA, Messing RO, Levine JD (2006) Ethanol withdrawal induces hyperalgesia mediated by PKCepsilon. Eur J Neurosci 24:197-204.

Dina OA, Khasar SG, Gear RW, Levine JD (2009) Activation of Gi induces mechanical hyperalgesia poststress or inflammation. Neuroscience 160:501-507.

Fazli-Tabaei S, Yahyavi SH, Alagheband P, Samie HR, Safari S, Rastegar F, Zarrindast MR (2005) Cross-tolerance between antinociception induced by swim-stress and morphine in formalin test. Behav Pharmacol 16:613-619.

Franklin GM, Stover BD, Turner JA, Fulton-Kehoe D, Wickizer TM (2008) Early opioid prescription and subsequent disability among workers with 
back injuries: the Disability Risk Identification Study Cohort. Spine (Phila Pa 1976) 33:199-204.

Galeotti N, Stefano GB, Guarna M, Bianchi E, Ghelardini C (2006) Signaling pathway of morphine induced acute thermal hyperalgesia in mice. Pain 123:294-305.

Girardot MN, Holloway FA (1984) Intermittent cold water stress-analgesia in rats: cross-tolerance to morphine. Pharmacol Biochem Behav 20: 631-633.

Han SK, Mancino V, Simon MI (2006) Phospholipase Cbeta 3 mediates the scratching response activated by the histamine $\mathrm{H} 1$ receptor on C-fiber nociceptive neurons. Neuron 52:691-703.

Hay JL, White JM, Bochner F, Somogyi AA, Semple TJ, Rounsefell B (2009) Hyperalgesia in opioid-managed chronic pain and opioid-dependent patients. J Pain 10:316-322.

Hucho TB, Dina OA, Levine JD (2005) Epac mediates a cAMP-to-PKC signaling in inflammatory pain: an isolectin $\mathrm{B} 4(+)$ neuron-specific mechanism. J Neurosci 25:6119-6126.

Joseph EK, Levine JD (2004) Caspase signalling in neuropathic and inflammatory pain in the rat. Eur J Neurosci 20:2896-2902.

Joseph EK, Chen X, Khasar SG, Levine JD (2004) Novel mechanism of enhanced nociception in a model of AIDS therapy-induced painful peripheral neuropathy in the rat. Pain 107:147-158.

Joseph EK, Bogen O, Alessandri-Haber N, Levine JD (2007) PLC-beta 3 signals upstream of PKC epsilon in acute and chronic inflammatory hyperalgesia. Pain 132:67-73.

Joseph EK, Chen X, Bogen O, Levine JD (2008) Oxaliplatin acts on IB4positive nociceptors to induce an oxidative stress-dependent acute painful peripheral neuropathy. J Pain 9:463-472.

Kalso E, Edwards JE, Moore RA, McQuay HJ (2004) Opioids in chronic non-cancer pain: systematic review of efficacy and safety. Pain 112: 372-380.

Kelly E, Bailey CP, Henderson G (2008) Agonist-selective mechanisms of GPCR desensitization. Br J Pharmacol 153 [Suppl 1]:S379-S388.

Khasar SG, Ho T, Green PG, Levine JD (1994) Comparison of prostaglandin E1- and prostaglandin E2-induced hyperalgesia in the rat. Neuroscience 62:345-350.

Khasar SG, Burkham J, Dina OA, Brown AS, Bogen O, Alessandri-Haber N, Green PG, Reichling DB, Levine JD (2008) Stress induces a switch of intracellular signaling in sensory neurons in a model of generalized pain. J Neurosci 28:5721-5730.

King AP, Hall KE, Macdonald RL (1999) kappa- and mu-Opioid inhibition of N-type calcium currents is attenuated by 4beta-phorbol 12-myristate 13 -acetate and protein kinase $\mathrm{C}$ in rat dorsal root ganglion neurons. J Pharmacol Exp Ther 289:312-320.

Kline RH 4th, Wiley RG (2008) Spinal mu-opioid receptor-expressing dorsal horn neurons: role in nociception and morphine antinociception. J Neurosci 28:904-913.

Kohno T, Ji RR, Ito N, Allchorne AJ, Befort K, Karchewski LA, Woolf CJ (2005) Peripheral axonal injury results in reduced mu opioid receptor pre- and post-synaptic action in the spinal cord. Pain 117:77-87.

Lewis JW, Sherman JE, Liebeskind JC (1981) Opioid and non-opioid stress analgesia: assessment of tolerance and cross-tolerance with morphine. J Neurosci 1:358-363.

Liu JG, Anand KJ (2001) Protein kinases modulate the cellular adaptations associated with opioid tolerance and dependence. Brain Res Brain Res Rev 38:1-19.

Liu JG, Prather PL (2001) Chronic exposure to mu-opioid agonists produces constitutive activation of mu-opioid receptors in direct proportion to the efficacy of the agonist used for pretreatment. Mol Pharmacol 60:53-62.

Mao J, Price DD, Mayer DJ (1995) Mechanisms of hyperalgesia and morphine tolerance: a current view of their possible interactions. Pain 62:259-274.

Mathew NT, Stubits E, Nigam MP (1982) Transformation of episodic migraine into daily headache: analysis of factors. Headache 22:66-68.

Mathews JL, Smrcka AV, Bidlack JM (2008) A novel Gbetagamma-subunit inhibitor selectively modulates mu-opioid-dependent antinociception and attenuates acute morphine-induced antinociceptive tolerance and dependence. J Neurosci 28:12183-12189.

McCleane G, Smith HS (2007) Opioids for persistent noncancer pain. Anesthesiol Clin 25:787-807.

Mercadante S, Arcuri E (2005) Hyperalgesia and opioid switching. Am J Hosp Palliat Care 22:291-294.

Mestek A, Hurley JH, Bye LS, Campbell AD, Chen Y, Tian M, Liu J, Schulman $\mathrm{H}, \mathrm{Yu} \mathrm{L}$ (1995) The human mu opioid receptor: modulation of functional desensitization by calcium/calmodulin-dependent protein kinase and protein kinase C. J Neurosci 15:2396-2406.

Murthy KS, Makhlouf GM (1996) Opioid mu, delta, and kappa receptorinduced activation of phospholipase C-beta 3 and inhibition of adenylyl cyclase is mediated by Gi2 and $\mathrm{G}(\mathrm{o})$ in smooth muscle. Mol Pharmacol 50:870-877.

Newton PM, Kim JA, McGeehan AJ, Paredes JP, Chu K, Wallace MJ, Roberts AJ, Hodge CW, Messing RO (2007) Increased response to morphine in mice lacking protein kinase C epsilon. Genes Brain Behav 6:329-338.

Ono T, Inoue M, Rashid MH, Sumikawa K, Ueda H (2002) Stimulation of peripheral nociceptor endings by low dose morphine and its signaling mechanism. Neurochem Int 41:399-407.

Parada CA, Yeh JJ, Joseph EK, Levine JD (2003) Tumor necrosis factor receptor type-1 in sensory neurons contributes to induction of chronic enhancement of inflammatory hyperalgesia in rat. Eur J Neurosci 17:1847-1852.

Parada CA, Reichling DB, Levine JD (2005) Chronic hyperalgesic priming in the rat involves a novel interaction between cAMP and PKCepsilon second messenger pathways. Pain 113:185-190.

Reichling DB, Levine JD (2009) Critical role of nociceptor plasticity in chronic pain. Trends Neurosci 32:611-618.

Rosenblum A, Marsch LA, Joseph H, Portenoy RK (2008) Opioids and the treatment of chronic pain: controversies, current status, and future directions. Exp Clin Psychopharmacol 16:405-416.

Sánchez-Blázquez P, Gómez-Serranillos P, Garzón J (2001) Agonists determine the pattern of G-protein activation in mu-opioid receptor-mediated supraspinal analgesia. Brain Res Bull 54:229-235.

Savage SR (1996) Long-term opioid therapy: assessment of consequences and risks. J Pain Symptom Manage 11:274-286.

Shi TJ, Liu SX, Hammarberg H, Watanabe M, Xu ZQ, Hökfelt T (2008) Phospholipase $\mathrm{C}\{$ beta $\} 3$ in mouse and human dorsal root ganglia and spinal cord is a possible target for treatment of neuropathic pain. Proc Natl Acad Sci U S A 105:20004-20008.

Smith FL, Lohmann AB, Dewey WL (1999) Involvement of phospholipid signal transduction pathways in morphine tolerance in mice. Br J Pharmacol 128:220-226.

Szikszay M, Benedek G (1989) Tolerance to morphine induced by chronic mild environmental stressors. Acta Physiol Hung 73:447-453.

Wang D, Raehal KM, Lin ET, Lowery JJ, Kieffer BL, Bilsky EJ, Sadée W (2004) Basal signaling activity of mu opioid receptor in mouse brain: role in narcotic dependence. J Pharmacol Exp Ther 308:512-520.

Wang HY, Burns LH (2006) Gbetagamma that interacts with adenylyl cyclase in opioid tolerance originates from a Gs protein. J Neurobiol 66:1302-1310.

Watkins LR, Hutchinson MR, Rice KC, Maier SF (2009) The "toll" of opioid-induced glial activation: improving the clinical efficacy of opioids by targeting glia. Trends Pharmacol Sci 30:581-591.

Webster BS, Verma SK, Gatchel RJ (2007) Relationship between early opioid prescribing for acute occupational low back pain and disability duration, medical costs, subsequent surgery and late opioid use. Spine (Phila Pa 1976) 32:2127-2132.

Wiesenfeld-Hallin Z, Xu XJ, Hökfelt T (2002) The role of spinal cholecystokinin in chronic pain states. Pharmacol Toxicol 91:398-403.

Wilkinson SM, Becker WJ, Heine JA (2001) Opiate use to control bowel motility may induce chronic daily headache in patients with migraine. Headache 41:303-309.

Xie W, Samoriski GM, McLaughlin JP, Romoser VA, Smrcka A, Hinkle PM, Bidlack JM, Gross RA, Jiang H, Wu D (1999) Genetic alteration of phospholipase $\mathrm{C}$ beta3 expression modulates behavioral and cellular responses to mu opioids. Proc Natl Acad Sci U S A 96:10385-10390. 